\title{
PREVALENCE OF BLOOD DONOR DEFERRAL AND ITS DISTRIBUTION BY SEX, TYPE OF DEFERRAL AND CAUSES IN POPULATION OF KARACHI, PAKISTAN
}

\author{
Sehrish Khurshid ${ }^{1}$, Rabbia Tariq ${ }^{2}$, Javeria Qureshi ${ }^{3}$, Farmanullah Shah ${ }^{4}$ \\ Departments of Pathology, ${ }^{1}$ Hamdard University, Karachi \& ${ }^{2}$ Isra University, Hyderabad, ${ }^{3}$ Department of \\ Hematology, Sindh Institute of Urology and Transplantation, Karachi, ${ }^{4}$ Gastroenterology Unit, MMM Teaching \\ Hospital, D.I.Khan, Pakistan
}

\begin{abstract}
Background: Donor selection is an important step for safe blood transfusion. The objectives of this study were to determine prevalence of blood donor deferral and its distribution by sex, type of deferral and causes in population of Karachi, Pakistan.

Materials \& Methods: This cross-sectional study was conducted at Department of Pathology, Hamdard University, Karachi, Pakistan from July 1, 2019 to June 30, 2020. Hamdard University Hospital, Karachi is assumed to cater 1.5 million population. With $1 \%$ donors, population at risk was 15,000 . With $10 \%$ donor deferral, $1.073 \%$ margin of error and $95 \%$ confidence interval, sample size was calculated as 2,503. The technique was consecutive nonprobability. Sex, age in years, weight, temperature, blood pressure and pulse were noted. Tests for CBC, blood grouping, hepatitis B, Hepatitis C, HIV, malaria and syphilis were done. Donor selection criteria included age range 18-60 years, weight $\geq 50 \mathrm{~kg}$, pulse rate $60-100 / \mathrm{min}$, systolic blood pressure $101-150 \mathrm{mmHg}$, diastolic blood pressure $60-100 \mathrm{mmHg}$, temperature $\leq 99^{\circ} \mathrm{F}$, hemoglobin $\geq 13.0 \mathrm{~g} / \mathrm{dl}$ for men and $\geq 12.5 \mathrm{~g} / \mathrm{dl}$ for women. All categorical variables were analyzed by count and percentage with $80 \% \mathrm{Cl}$.

Results: Out of 2,503 donors, 2,493 (99.7\%) were men and $10(0.3 \%)$ women. Frequency of deferral was 139 (5.5533\%), including 129 (5.1538\%) men and 10 (0.3995\%) women and $58(2.3172 \%)$ temporary and $81(3.2361 \%)$ permanent. Causes of temporary deferral were; anemia $33(1.3184 \%)$, low weight $8(0.3196 \%)$, acute infection and on medication each $5(0.1998 \%)$, donation of blood in last 8 weeks $4(0.1598 \%)$ and hypotension $3(0.1198 \%)$ cases. Causes of permanent deferral were; HCV 32 (1.2784\%), HBV 30 (1.1985\%), syphilis 17 (0.6792\%), HIV and diabetes mellitus each one $(0.04 \%)$ case.

Conclusion: Prevalence of blood donor deferral was $5.55 \%$ in our study, which is almost half of all the cited studies here from global, regional, national and local populations. Prevalence in men was many times higher than women and prevalence of permanent causes was higher than temporary causes. Anemia and HCV were the two major causes of deferral in our study. Proper donor selection is a key of safe blood transfusion. Appropriate measures are needed to prevent causes of deferral.
\end{abstract}

KEY WORDS: Blood Donors; Blood Donation; Blood Transfusion; Anemia; Hepatitis B; Hepatitis C; Syphilis; Hypotension; Diabetes Mellitus.

Cite as: Khurshid S, Tariq R, Qureshi J, Shah F. Prevalence of blood donor deferral and its distribution by sex, type of deferral and causes in population of Karachi, Pakistan. Gomal J Med Sci 2020 Oct-Dec; 18(4):148-55. https://doi.org/10.46903/gjms/18.04.809

\section{INTRODUCTION}

1.1 Background: Blood transfusion is an important life-saving procedure; therefore donor selection is

\section{Corresponding Author:}

Dr. Sehrish Khurshid

Assistant Professor, Department of Pathology

Hamdard University, Karachi, Pakistan

E-mail: sehrishk2009@hotmail.com

Date Submitted:

Date Revised:

Date Accepted:
$15-08-2020$

$12-10-2020$

$22-11-2020$ an essential step in transfusion practice. ${ }^{1}$ Safe blood transfusion is a sign of quality blood banks. ${ }^{2}$ The criteria of donor selection are important for health of both the donor and the recipient. ${ }^{3}$ Donor should be screened according to national guidelines. Donor screening encompasses medical history, physical examination and serological testing for transfusion transmitted infections in order to protect the recipient from the blood related infections. Obtaining accurate and complete answers of donors in assessing transfusion transmitted infections is a key to safe blood transfusion. 
According to $\mathrm{WHO}$, worldwide collection of blood is 81 million units per year. ${ }^{4}$ Approximately 1.5 million pints of blood is collected per year in Pakistan and majority blood donors are replacement donors. ${ }^{5}$ Less number of voluntary donors is due to misconceptions and fear regarding blood donation. ${ }^{6}$

Deferral could be temporary or permanent on the basis of confirmed or suspicion infectious, hematological disease or any other medical condition that will influence the health of donor or recipient. ${ }^{7}$ All deferred donors should be counseled properly about the reason of deferral in confidential manner. ${ }^{8}$ In most cases, the donated blood is used to correct anemia as in thalassemia, hematological malignancy and to compensate losses due to trauma, surgery or obstetric complications. ${ }^{9}$

Zou, et al. ${ }^{10}$ from Rockvilli, Maryland, USA reported the data from American Red Cross Blood Services for years 2001 through 2006, showing 47,814,370 donors, with the frequency of deferral as $6,120,240$ $(6,120,240 * 100 / 47,814,370=12.8000 \%)$.

Shah, et al. ${ }^{11}$ reported 586,159 voluntary donors from American Red Cross Southern Region in the metropolitan Atlanta area in 2004 to 2008 , with the frequency of deferral as 79,214 $(79,214 * 100 / 586,159=13.5140 \%)$.

Charles, et al. ${ }^{12}$ from National Blood Transfusion Centre, Port of Spain, Trinidad and Tobago, reported 11,346 donors, with frequency of deferral as 4043 (35.6337\%).

Valerian, et al. ${ }^{7}$ reported 14,377 donors from Tanzania for the year 2016, including $11,377(79.1333 \%)$ men and $3,000(20.8667 \%)$ women. The frequency of deferral was $1,829(1,829 * 100 / 14,377=12.7217 \%)$, including $1,361(1,361 * 100 / 14,377=9.4665 \%)$ men and $468(468 * 100 / 14,377=3.2552 \%)$ women, and $927(927 * 100 / 14,377=6.4478 \%)$ temporary and $902(902 * 100 / 14,377=6.2739 \%)$ permanent deferrals. Some causes of temporary deferral were; anemia $162(162 * 100 / 14,377=1.1267 \%)$, syphilis $149(149 * 100 / 14,377=1.0363 \%)$ and medications $84(0.5842 \%)$. Some causes of permanent deferral were; HBV positive $489(489 * 100 / 14,377=3.4012 \%)$, HIV positive $198\left(198^{*} 100 / 14,377=1.3771\right)$ and HCV positive $31(31 * 100 / 14,377=0.2156 \%)$.

Okoroiwu, et al. ${ }^{8}$ reported 1,886 donors from Southern Nigeria for the year 2016, including 1,853 men $(98.2502 \%)$ and 33 women $(1.7808 \%)$. The frequency of deferral was 164 (164* $100 / 1886=8.6956 \%)$, including $153(153 * 100 / 1886$ $=8.1124 \%)$ men and $11(11 * 100 / 1886=0.5832 \%)$ women and $51(51 * 100 / 1886=2.7041 \%)$ temporary and $113(113 * 100 / 1886=5.9915 \%)$ permanent deferrals. Causes of temporary deferral were; anemia $36(36 * 100 / 1886=1.9088 \%)$ and syphilis $15(15 * 100 / 1886=0.7953 \%)$. Causes of permanent deferral were; HBV positive
$52(52 * 100 / 1886=2.7571 \%)$, HCV positive 31 $(31 * 100 / 1886=1.6436 \%)$ and HIV positive 31 $(31 * 100 / 1886=1.6436 \%)$.

Birjandi, et al. ${ }^{13}$ from Isfahan, Iran reported 197,757 volunteer donors who presented between March 20, 2007 and March 19, 2008. These included $188,977(188,977 * 100 / 197,757=95.5602 \%)$ male and $8,780(8,780 * 100 / 197,757=4.4398 \%)$ female donors. The frequency of deferral was 50,727 $(50,727 * 100 / 197,757=25.6511 \%)$, including 45,929 $(45,929 * 100 / 197,757=23.2249 \%)$ males and $4,798(4,798 * 100 / 197,757=2.4262 \%)$ females, and $44,920(44,920 * 100 / 197,757=22.7147 \%)$ temporary and $5,807(5,807 * 100 / 197,757=2.9364 \%)$ permanent. Few causes were; medication $4625(4625 * 100 / 197,757=2.3387 \%)$, anemia $4238(4238 * 100 / 197,757=2.1430 \%)$, low weight $164 \quad(164 * 100 / 197,757=0.0829)$ and blood donation interval of 3 months 137 $(137 * 100 / 197,757=0.0692 \%) .{ }^{13}$

Kasraian, et al. ${ }^{14}$ from Shiraz, Iran reported 141,820 volunteer donors from March 21, 2009 to March 21, 2010, including $132,950(132,950 * 100 / 141,820=93.7456 \%)$ men and $8,870(8,870 * 100 / 141,820=6.2544 \%)$ women. The frequency of deferral was 43,839 $(43,839 * 100 / 141,820=30.9117 \%)$, including 41,866 $(41,866 * 100 / 141,820=29.5205 \%)$ temporary and $1,973(1973 * 100 / 141,820=1.3912 \%)$ permanent deferrals. ${ }^{14}$

Rehman, et al. ${ }^{4}$ reported 53,950 donors from Aligarh, India for the duration from 2007-2011, including 51,266 men (95.0250\%) and 2,684 women $(4.9750 \%)$. The frequency of deferral was 6,690 $(6,690 * 100 / 53,950=12.4003 \%)$, including 4,262 $(4,262 * 100 / 53,950=7.8999 \%)$ temporary and 2,428 $(2,428 * 100 / 53,950=4.5004 \%)$ permanent deferrals, and $6,142(6,142 * 100 / 53,950=11.3846 \%)$ men and $548(548 * 100 / 53,950=1.0157 \%)$ women. Some causes were; anemia $765(765 * 100 / 53,950=1.4179 \%)$, malaria in last 3 months $505(0.9360 \%)$, weight $<45 \mathrm{~kg} 454(0.8415 \%)$, syphilis for 1 month 164 $(164 * 100 / 53,950=0.3039 \%)$, HBV positive 1,571 $(1571 * 100 / 53,950=2.9119 \%)$, HCV positive 169 $(169 * 100 / 53,950=0.3132 \%)$ and HIV positive 196 $(196 * 100 / 53,950=0.3629 \%)$.

Sundar, et al. ${ }^{15}$ from Bungalore, India reported 16,706 donors from Jan. 2005 to Dec. 2007, including $14,822(14,822 * 100 / 16,706=88.7226 \%)$ men and $1884(1884 * 100 / 16.706=11.2774 \%)$ women donors. The frequency of deferral was $976(976 * 100 / 16,706=5.8422 \%)$, including $602(602 * 100 / 16,706=3.6035 \%)$ men and 374 $(374 * 100 / 16,706=2.2387 \%)$ women, and 820 $(820 * 100 / 16,706=4.9084 \%)$ temporary and 156 $(156 * 100 / 16,706=0.9338 \%)$ permanent deferrals. Some causes of deferral were; anemia 224 $(224 * 100 / 16,706=1.3408 \%)$, underweight 115 $(115 * 100 / 16,706=0.6883 \%)$ and hypertension \& 
cardiac problems $112\left(112^{\star} 100 / 16,706=0.6704 \%\right)$. Agnihotri ${ }^{16}$ reported 6,357 donors from Chinchwad, Pune, Maharashtra, India from Jan. 2008 to June 2009 , including 5,723 men (90.0267\%) and 634 women (9.9733\%). The frequency of deferral was 736 $(11.5777 \%)$, including $397(397 * 100 / 6,357=6.2450 \%)$ men and $339(339 * 100 / 6,357=5.3327 \%)$ women. Some caused were; anemia $6.5 \%$, underweight $0.3 \%$, antibiotics \& other medications $0.8 \%$, previous donation within three months $0.2 \%$ and history of jaundice/ HBV/HCV $0.1 \%$.

Shahtaj, et al. ${ }^{17}$ for the years 2009 to 2011 from Peshawar, Pakistan reported 3,617 donors, inclusion 3,554 (98.2582\%) men and 63 (1.7417\%) women. The frequency of deferral was 315 $\left(315^{*} 100 / 3,617=8.7088 \%\right)$, including 256 temporary $(256 * 100 / 3617=7.0776 \%)$ and $59(59 * 100 /$ $3,617=1.6311 \%)$ permanent deferrals, and 270 $(270 * 100 / 3,617=7.4647 \%)$ men and 45 women $\left(45^{*} 100 / 3,617=1.2441 \%\right)$. Major causes of deferral were; hypotension $70(70 * 100 / 3617=1.9353 \%)$, anemia $42(42 * 100 / 3,617=1.1611 \%)$, hypertension $35(35 * 100 / 3617=0.9676 \%)$, blood donation in last 3 months $26(26 * 100 / 3,617=0.7188 \%)$, low weight $19(19 * 100 / 3,617=0.5252 \%)$ and diabetes mellitus $2(2 * 100 / 3,617=0.0552 \%)$.

Tufail, et al. ${ }^{2}$ reported in 2013 from Islamabad, Pakistan 1,833 donors. The frequency of deferrals was $249(249 * 100 / 1,833=13.5842 \%)$; including 238 $(12.9841 \%)$ men $(238 * 100 / 1,833=8.9470 \%)$ and 11 $(0.6001 \%)$ women $\left(11^{*} 100 / 1,833=8.9470 \%\right)$, and 164 $(8.9470 \%)$ temporary $\left(164^{*} 100 / 1,833=8.9470 \%\right)$ and $85(4.6372 \%)$ permanent $\left(85^{\star} 100 / 1,833=4.6372 \%\right)$ deferrals. Some causes were; anemia 90 $(90 * 100 / 1,833=4.9099 \%)$, HCV positive 57 (3.1096\%), thrombocytopenia 34 (1.8548), HBsAg positive $15(0.8183 \%)$, acute infection $12(0.6546 \%)$, HIV positive $3(3 * 100 / 1,833=0.1636 \%)$ and underweight 2 (0.1091\%).

Khalid, et al. ${ }^{18}$ reported 4,225 donors from Islamabad, Pakistan from Oct. 1, 2016 to March 31,2017 , including 4,199 (99.3846\%) men and $26(0.6154 \%)$ women. The frequency of deferral was $410(410 * 100 / 4,225=9.7041 \%)$. Some causes were; anemia $141(141 * 100 / 4,225=$ $3.3372 \%)$, within three months of previous donation $10(10 * 100 / 4,225=0.2366 \%)$, underweight $7 \quad(7 * 100 / 4,225=0.1656 \%)$, HBV $70(70 * 100 / 4,225=1.6568 \%), \mathrm{HCV}$ $66(66 * 100 / 4,225=1.5621 \%)$ and HIV 5 $\left(5^{\star} 100 / 4,225=0.1183 \%\right)$ cases.

Iqbal, et al. ${ }^{1}$ reported for the year 2019 from Multan, Pakistan $433(13.9330 \%)$ cases of deferrals from a sample of 3,348 ; including 427 $(427 * 100 / 3,348=12.7538 \%)$ men and 6 $(6 * 100 / 3,348=0.1792 \%)$ women. Some causes were; anemia $218(218 * 100 / 3,348=6.5113 \%), \mathrm{HCV}$ positive 83 (2.4790\%), HBsAg positive 49 (1.4635\%), syphilis $36(1.0752)$, thrombocytopenia $15(0.4480)$ and acute infection $14(14 * 100 / 3,348=0.4181 \%)$ cases, with no case of HIV positive.

Khurram, et al. ${ }^{19}$ reported for the years 2012-2014 from Karachi, Pakistan 25,901 donors, including $25,679(99.1428 \%)$ men and $222(0.8571 \%)$ women. The frequency of deferral was 3,156 $(3156 * 100 / 25901=12.1848 \%)$, including 2,876 $(2876 * 100 / 25901=11.1038 \%)$ temporary and $280(280 * 100 / 25901=1.0810 \%)$ permanent. Common causes of deferral were; anemia 971 $(971 * 100 / 25901=3.7488 \%)$, HBV positive 147 $(147 * 100 / 25,901=0.5675 \%)$, thrombocytopenia 611 $(611 * 100 / 25,901=2.3589 \%)$ and previous history of jaundice $192(192 * 100 / 25,901=0.7412 \%)$.

Sultan, et al..$^{20}$ reported for the period from Jan. 2014 to Dec. 2015 from Karachi, Pakistan 3,103 (8.3969\%) cases of deferrals from a sample of 36,954 ; including 2,612 $(2612 * 100 / 36,954=7.0682 \%)$ men and $491(491 * 100 / 3,348=1.3287 \%)$ women, with anemia as most common cause in 2,445 $(2445 * 100 / 36,954=6.6163 \%)$ cases.

1.2 Research Problems (RPs), Knowledge Gaps (KGs), Research Questions (RQs) \& Rationale: We don't know the recent prevalence of blood donor deferral and its distribution by sex, type of deferral and causes in population of Karachi, Pakistan. This unawareness of four pieces of information are our four RPs. Literature didn't explored these information. These are our four KGs. What would be the recent prevalence of blood donor deferral and its distribution by sex, type of deferral and causes in population of Karachi, Pakistan are our four RQs. To answer these four RQs, to fill these four KGs and to solve these four RPs is the rationale of our project.

1.3 Research Objectives (ROs): The four objectives of this study were;

$\mathbf{R Q} 1$ 1: to determine the prevalence of blood donor deferral in population of Karachi, Pakistan.

RQ 2-4: to determine the distribution of blood donor deferral by sex, type of deferral and causes in population of Karachi, Pakistan.

1.4 Significance: Having burden of a problem (disease/ health related state) in hand, one can optimally allocate required and available resources to combat that problem. Having cause of a problem in hand, one can plan for intervention to prevent and control that problem. We will go for both these epidemiological enquiries in our project.

\section{MATERIALS AND METHODS}

2.1 Design, Setting \& Duration: This cross-sectional study was conducted at the Department of Pathology, Hamdard University, Karachi, Pakistan from July 1, 2019 to June 30, 2020. The data was collected from Hamdard University Hospital Blood Bank, Taj 
Medical Complex, MA Jinnah Road, Karachi.

2.2 Population, Sample Size \& Technique and Sample Selection: Karachi is most populous city of Pakistan, with estimated population of $15,741,000$ for the year 2019. Out of this, our hospital is assumed to provide medical services to some 1.5 million population. With one percent $(1 \%)$ donors in 1.5 million population; the population of donors/ population at risk will be 15,000 . With 15,000 population at risk, $10 \%$ prevalence of donor deferral, $1.073 \%$ margin of error and $95 \%$ confidence interval, the sample size was calculated as 2,503 , using Raosoft ${ }_{\circledast}$ online sample size calculator. The technique was consecutive non-probability.

Selection criteria of donors were according to the standard operating procedures which were based on national guidelines. Donor selection criteria included age ranges $18-60$ years, weight of $\geq 50 \mathrm{Kg}$, pulse rate $60-100 / \mathrm{min}$, systolic blood pressure $100-150$ $\mathrm{mmHg}$ and diastolic blood pressure $60-100 \mathrm{mmHg}$, Temperature $\leq 99^{\circ} \mathrm{F}$, hemoglobin $\geq 13.0 \mathrm{~g} / \mathrm{dl}$ for men and $\geq 12.5 \mathrm{~g} / \mathrm{dl}$ for women. ${ }^{21}$

2.3 Conduct of Procedure: All donors who had come for blood donation were interviewed and donors were assured that all information would be kept confidential. Age in years, sex, weight in kg, temperature, blood pressure and pulse were noted. Tests for CBC, blood grouping, hepatitis B, hepatitis C, HIV, malaria and syphilis were done. $\mathrm{CBC}$ was performed on automated hematology analyzer Sysmex XP 300 (Japan), blood grouping was done by tube method, HBsAg, Anti HCV and Anti HIV was performed by chemiluminescence method on Roche e411 (Switzerland), malaria and syphilis was performed by ICT method manufactured by Acro Biotech Inc., (USA).

2.4 Data Collection \& Analysis Plan: Sex, age in years, type of deferral and presence of deferral were four variables. Continuous/ numeric variable such as age was analyzed by mean, minimum, maximum, range and SD. All the categorical variables were analyzed by count and percentage for the sample and by $80 \% \mathrm{Cl}$ as estimated parameters for the population using Wilson score interval. The interpretation for the confidence interval is that if it calculated over an infinite number of samples with a sample size of 2,$503 ; 80 \%$ of the intervals will contain the true population parameter. The comparison for prevalence/ distribution between the attributes/ groups is based on Cls. If the Cls overlap, there is no difference, otherwise different (higher or lower). Data was analyzed on an online statistical calculator "Statistics Kingdom". ${ }^{22}$

\section{RESULTS}

Out of 2,503 donors, 2,493 (99.7\%) were men and $10(0.3 \%)$ women. The mean age of the sample was $32.0 \pm 7.2$ (18-60, range 42$)$ years. Out of these 2,503 donors, the frequency of deferral was $139(139 * 100 / 2,503=5.5533 \%)(80 \%$ Cl $4.9953 \%-$ $6.1696 \%)$.

The distribution of 139 deferred donors by sex was; 129 (5.1538\%) men and 10 (0.3995\%) women. Here the prevalence in men was many times higher than women. (Table 1)

The distribution of 139 deferred donors by type of deferral was; $58(2.3172 \%)$ donors were temporarily deferred and 81 (3.2361\%) were permanently deferred. Here the prevalence of permanent deferrals was higher than temporary deferrals. (Table 1)

Anemia was the most common cause of temporary deferral in $33\left(33^{*} 100 / 2,503=1.3184 \%\right)$ cases, while hepatitis $\mathrm{C}$ positivity was the most common cause of permanent deferral in $32(32 * 100 / 2,503=1.2784 \%)$ cases. (Table 2)

Table 1: Distribution of 139 cases of blood donor deferral by sex and type in population of Karachi, Pakistan $(n=139 / 2,503)$

\begin{tabular}{|c|c|c|c|c|c|}
\hline \multirow{2}{*}{ Variable } & \multirow{2}{*}{ Attributes } & \multicolumn{2}{|r|}{ Sample statistics } & \multicolumn{2}{|c|}{$80 \% \mathrm{Cl}$ for proportion } \\
\hline & & Count & Percentage & Lower & Upper \\
\hline \multirow{2}{*}{ Sex } & Men & 129 & $129 * 100 / 2,503=5.1538 \%$ & 4.6160 & 5.7501 \\
\hline & Women & 10 & $10 * 100 / 2,503=0.3995 \%$ & 0.2672 & 0.5967 \\
\hline \multirow{2}{*}{ Type of deferral } & Temporary & 58 & $58 * 100 / 2,503=2.3172 \%$ & 1.9619 & 2.7350 \\
\hline & Permanent & 81 & $81 * 100 / 2,503=3.2361 \%$ & 2.8126 & 3.7209 \\
\hline \multicolumn{2}{|l|}{ Total } & 139 & $139 * 100 / 2,503=5.5533 \%$ & 4.9953 & 6.1697 \\
\hline
\end{tabular}


Table 2: Distribution of 139 cases of blood donor deferral by causes deferral in population of Karachi, Pakistan $(n=139 / 2,503)$

\begin{tabular}{|l|c|c|c|c|}
\hline \multirow{2}{*}{ Causes of deferral } & \multicolumn{2}{|c|}{ Sample statistics } & \multicolumn{2}{c|}{$\mathbf{8 0 \%}$ Cl for proportion } \\
\cline { 2 - 5 } & Count & Percentage & Lower & Upper \\
\hline A. Temporary causes & $\mathbf{5 8}$ & $\mathbf{2 . 3 1 7 2}$ & $\mathbf{1 . 9 6 1 9}$ & $\mathbf{2 . 7 3 5 0}$ \\
\hline Anemia & 33 & 1.3184 & 1.0565 & 1.6441 \\
\hline Low weight & 08 & 0.3196 & 0.2040 & 0.5003 \\
\hline Acute infection & 05 & 0.1998 & 0.1135 & 0.3513 \\
\hline On medications & 05 & 0.1998 & 0.1135 & 0.3513 \\
\hline Donated blood in last 8 weeks & 04 & 0.1598 & 0.0851 & 0.2998 \\
\hline Hypotension & 03 & 0.1198 & 0.0581 & 0.2470 \\
\hline B. Permanent causes & $\mathbf{8 1}$ & $\mathbf{3 . 2 3 6 1}$ & $\mathbf{2 . 8 1 2 6}$ & $\mathbf{3 . 7 2 0 9}$ \\
\hline HCV positive & 32 & 1.2784 & 1.0209 & 1.5998 \\
\hline HBsAg positive & 30 & 1.1985 & 0.9501 & 1.5111 \\
\hline Syphilis positive & 17 & 0.6792 & 0.4987 & 0.9243 \\
\hline HIV positive & 01 & 0.0400 & 0.0119 & 0.1334 \\
\hline Diabetes mellitus & 01 & 0.0400 & 0.0119 & 0.1334 \\
\hline Total cases deferred & $\mathbf{1 3 9}$ & $\mathbf{5 . 5 5 3 3}$ & $\mathbf{4 . 9 9 5 3}$ & $\mathbf{6 . 1 6 9 7}$ \\
\hline Cases not deferred & $\mathbf{2 , 3 6 4}$ & $\mathbf{9 4 . 4 4 6 7}$ & $\mathbf{9 3 . 8 3 0 3}$ & $\mathbf{9 5 . 0 0 4 7}$ \\
\hline Total & $\mathbf{2 , 5 0 3}$ & $\mathbf{1 0 0}$ & Population parameters \\
\hline
\end{tabular}

\section{DISCUSSION}

\subsection{Prevalence of blood donor deferral}

The prevalence of blood donor deferral was 5.5533\% (80\% Cl 4.9953\%-6.1696\%) in our population.

Higher prevalence than our study (higher than upper limit of our confidence interval) was reported in sixteen studies from different local, national, regional and global populations/ studies as follow; $12.18 \%$ by Khurram, et al. ${ }^{19} \& 8.39 \%$ by Sultan, et al. ${ }^{20}$ from Karachi, Pakistan, $13.93 \%$ by lqbal, et al. ${ }^{1}$ from Multan, Pakistan, $8.94 \%$ by Tufail, et al. ${ }^{2} \& 9.70 \%$ by Khalid, et al. ${ }^{18}$ from Islamabad, Pakistan, $8.70 \%$ by Shahtaj, et al. ${ }^{17}$ from Peshawar, Pakistan, $12.40 \%$ by Rehman, et al. ${ }^{4}$ from Aligarh, India, $11.27 \%$ by Sundar, et al. ${ }^{15}$ from Bungalore, India, $11.57 \%$ by Agnihotri ${ }^{16}$ from Chinchwad, Pune, Maharashtra, India, $25.65 \%$ by Birjandi, et al. ${ }^{13}$ from Isfahan, Iran $\& 30.91 \%$ by Kasraian, et al. ${ }^{14}$ from Shiraz, Iran, $8.69 \%$ by Okoroiwu, et al. ${ }^{8}$ from Sokoto, northwestern Nigeria, $12.72 \%$ by Valerian, et al. ${ }^{7}$ from Moshi, Tanzania, $35.63 \%$ by Charles, et al. ${ }^{12}$ from Port of Spain, Islands of Trinidad and Tobago, $12.80 \%$ by Zou, et al. ${ }^{10}$ from Rockvilli, Maryland, USA and $13.51 \%$ by Shah, et al. ${ }^{11}$ from Atlanta, USA.

The difference in prevalence may be due to difference in selection criteria.

No studies could be retrieved with similar or lower prevalence than our study.
4.2 Distribution of blood donor deferral by sex

The prevalence of blood donor deferral was higher in men $5.1538 \%(80 \% \mathrm{Cl} 4.6160-5.7501)$ than women $0.3995 \%(80 \% \mathrm{Cl} 0.2672-0.5967)$ in our population. (Table 1)

Similar higher prevalence for men than women was reported by Khurram, et al. ${ }^{19}$ from Karachi, Pakistan as $12.04 \%$ vs. $0.13 \%$, Sultan, et al. ${ }^{20}$ from Karachi as $7.06 \%$ vs. $1.32 \%$, Iqbal, et al. ${ }^{1}$ from Multan, Pakistan as $12.75 \%$ vs. $0.17 \%$, Tufail, et al. ${ }^{2}$ from Islamabad, Pakistan as $12.98 \%$ vs. $0.60 \%$, Shahtaj, et al. ${ }^{17}$ from Peshawar, Pakistan as $8.70 \%$ vs. $1.24 \%$, Rehman, et al. ${ }^{4}$ from Aligarh, India as $11.38 \%$ vs. $1.01 \%$, Sundar, et al. ${ }^{15}$ from Bungalore, India as $3.60 \%$ vs. $2.23 \%$, Agnihotri ${ }^{16}$ from Chinchwad, Pune, Maharashtra, India as $6.24 \%$ vs. $5.33 \%$, Birjandi, et al. ${ }^{13}$ from Isfahan, Iran as $23.22 \%$ vs. $2.43 \%$, Okoroiwu, et al. $^{8}$ from Sokoto, Nigeria as $8.11 \%$ vs. $0.58 \%$, and Valerian, et al. ${ }^{7}$ from Moshi, Tanzania as $9.47 \%$ vs. $3.25 \%$.

Higher prevalence of deferral for men than women may be explained by the erroneous belief that men are healthier than women. Likewise fear of developing anemia, fear of weakness, pregnancy, breast feeding and false beliefs about blood donation may restrict many women from donating blood. ${ }^{23}$ Difficult vein in women may also be a problem in donating blood. ${ }^{24}$ 
No studies could be retrieved with similar prevalence for men and women or higher prevalence for women than men.

\subsection{Distribution of blood donor deferral by type of deferral}

The prevalence of permanent blood donor deferral $3.2361 \%(80 \% \mathrm{Cl} 2.8126-3.7209)$ was higher than temporary deferral $2.3172 \%(80 \% \mathrm{Cl} 1.9619-2.7350)$ in our population. (Table 1)

Similar to our study, Okoroiwu, et al. ${ }^{8}$ from Sokoto, Nigeria reported higher prevalence for permanent $5.99 \%$ than temporary deferrals $2.70 \%$.

Equal prevalence was reported by Valerian, et al. ${ }^{7}$ from Moshi, Tanzania as $6.45 \%$ temporary vs. $6.27 \%$ permanent.

Contrary to our findings, higher prevalence for temporary versus permanent deferrals was reported by Khurram, et al. ${ }^{19}$ from Karachi, Pakistan as $11.10 \%$ vs. $1.08 \%$, by Tufail, et al. ${ }^{2}$ from Islamabad, Pakistan as $8.94 \%$ vs. $4.64 \%$, by Khalid, et al. ${ }^{18}$ from Islamabad, Pakistan as $6.36 \%$ vs. $3.33 \%$, by Shahtaj, et al. ${ }^{17}$ from Peshawar, Pakistan as $7.07 \%$ vs. $1.08 \%$, by Sundar, et al. ${ }^{15}$ from Bungalore, India as $4.90 \%$ vs. $0.93 \%$, by Birjandi, et al. ${ }^{13}$ from Isfahan, Iran as $22.71 \%$ vs. $2.93 \%$, by Kasraian, et al. ${ }^{14}$ from Shiraz, Iran as $29.52 \%$ vs. $1.39 \%$, by Rehman, et al. ${ }^{4}$ from Aligarh, India as $7.90 \%$ vs. $7.50 \%$.

\subsection{Distribution of blood donor deferral by causes of deferral}

Prevalence of anemia in blood donors was $1.3184 \%$ (80\% Cl 1.05\%-1.64\%) in our population. (Table 2 )

Similar prevalence of anemia to our study was reported by Shahtaj, et al. ${ }^{17}$ from Peshawar, Pakistan as $1.16 \%$ \& by Rehman, et al. ${ }^{4}$ from Aligarh, India as $1.41 \%$. Higher prevalence than our study (higher than upper limit of our confidence interval) was reported in six studies as follows; $3.74 \%$ by Khurram, et al..$^{19} \&$ $6.61 \%$ by Sultan, et al..$^{2}$ from Karachi, Pakistan, $6.51 \%$ by lqbal, et al. ${ }^{1}$ from Multan, Pakistan, $4.90 \%$ by Tufail, et al. ${ }^{2} \& 3.33 \%$ by Khalid, et al. ${ }^{18}$ from Islamabad, Pakistan and $6.5 \%$ by Agnihotri ${ }^{16}$ from Chinchwad, Pune, Maharashtra, India. No studies could be retrieved with lower prevalence of anemia than our study.

Prevalence of low weight was $0.3196 \%(80 \% \mathrm{Cl}$ $0.20 \%-0.50 \%$ ) in our population. (Table 2 )

Similar prevalence of $0.3 \%$ was reported by Agnihotri ${ }^{16}$ from Chinchwad, Pune, Maharashtra, India. Higher prevalence than our study was reported from different studies as; $0.57 \%$ by Khurram, et al. ${ }^{19}$ from Karachi, Pakistan, $0.52 \%$ by Shahtaj, et al. ${ }^{17}$ from Peshawar, Pakistan, $0.84 \%$ by Rehman, et al. ${ }^{4}$ from Aligarh, India and $0.68 \%$ by Sundar, et al. ${ }^{15}$ from Bungalore, India. Lower prevalence than our study was reported from different studies as; $0.10 \%$ by Tufail, et al. ${ }^{2} \& 0.16 \%$ by Khalid, et al. ${ }^{18}$ from Islamabad and $0.08 \%$ by
Birjandi, et al. ${ }^{13}$ from Isfahan, Iran.

Prevalence of donor deferred due to medication was $0.1998 \%(80 \% \mathrm{Cl} 0.11 \%-0.35 \%)$ in our population. (Table 2)

Higher prevalence was reported as $0.52 \%$ by Khurram, et al. ${ }^{19}$ from Karachi, Pakistan, $0.51 \%$ by Rehman, et al. ${ }^{4}$ from Aligarh, India.0.8\% by Agnihotri ${ }^{16}$ from India and $0.73 \%$ by Valerian, et al. ${ }^{7}$ from Moshi, Tanzania. Lower prevalence than our study was reported $0.10 \%$ by Tufail, et al. ${ }^{2}$ and $0.11 \%$ by Khalid, et al. ${ }^{18}$ from Islamabad, Pakistan.

Prevalence of donor deferred due to infection was $0.1998 \%(80 \% \mathrm{Cl} 0.11 \%-0.35 \%)$ in our population. (Table 2)

High prevalence was reported in different studies as; $0.36 \%$ by Khurram, et al. ${ }^{19}$ from Karachi, Pakistan, $0.41 \%$ by lqbal, et al. ${ }^{1}$ from Multan, Pakistan, $0.65 \%$ by Tufail, et al. ${ }^{2}, 0.46 \%$ by Rehman, et al. ${ }^{4}$ from Aligarh, India, $1.01 \%$ by Sundar, et al. ${ }^{15}$ from Bungalore, India, $0.8 \%$ by Agnihotri ${ }^{16}$ from India and $0.34 \%$ by Valerian, et al. ${ }^{7}$ from Moshi, Tanzania. No studies could be retrieved with similar to or lower prevalence than our study.

Prevalence of low blood pressure was $0.1198 \%$ (80\% Cl $0.05 \%-0.24 \%$ ) in our population.

Higher prevalence was reported by Shahtaj, et al. ${ }^{17}$ from Peshawar, Pakistan 1.95\%. No studies could be retrieved with similar to or lower prevalence than our study.

Prevalence of donor deferred due to Hepatitis C virus was $1.0209 \%(80 \% \mathrm{Cl} 1.02 \%-1.59 \%)$ in our population. (Table 2)

Similar prevalence was reported as $1.56 \%$ by Khalid, et al. ${ }^{18}$ from Islamabad. Pakistan. Higher prevalence than our study was reported in four studies as follow; $2.47 \%$ by lqbal, et al. ${ }^{1}$ from Multan, Pakistan, $3.10 \%$ by Tufail, et $\mathrm{al}^{2}$ from Islamabad. Pakistan, $3.10 \%$ by Rehman, et al. ${ }^{4}$ from Aligarh, India, $1.64 \%$ by Okoroiwu, et al. ${ }^{8}$ from Sokoto, northwestern Nigeria. Lower prevalence than our study was reported as $0.21 \%$ by Valerian, et al. ${ }^{7}$ from Moshi, Tanzania.

Prevalence of donor deferred due to Hepatitis B virus was $1.19 \%$ (80\% Cl 1.02\%-1.59\%) in our population. (Table 2)

Similar prevalence was reported as $1.46 \%$ by lqbal, et al. ${ }^{1}$ from Multan, Pakistan. Higher prevalence than our study was reported in four studies as follow; $1.65 \%$ by Khalid, et al. ${ }^{18}$ from Islamabad. Pakistan, $2.91 \%$ by Rehman, et al. ${ }^{4}$ from Aligarh, India, $2.75 \%$ by Okoroiwu, et al. ${ }^{8}$ from Sokoto, northwestern Nigeria and $3.40 \%$ by Valerian, et al. ${ }^{7}$ from Moshi, Tanzania. Lower prevalence than our study was reported as $0.56 \%$ by Khurram, et al. ${ }^{19}$ from Karachi, Pakistan and $0.81 \%$ by Tufail, et $\mathrm{al}^{2}$ from Islamabad, Pakistan.

Prevalence of syphilis was $0.67 \%(80 \% \mathrm{Cl} 0.49 \%$ $0.92 \%$ ) in our population. 
Similar prevalence was reported as $0.91 \%$ by Sultan, et al. ${ }^{20}$ from Karachi and $0.79 \%$ by Okoroiwu, et al. ${ }^{8}$ from Sokoto, northwestern Nigeria. Higher prevalence was reported as $1.07 \%$ by lqbal, et al. ${ }^{1}$ from Multan, Pakistan and $1.03 \%$ by Valerian, et al. ${ }^{7}$ from Moshi, Tanzania. Lower prevalence than our study $0.30 \%$ was reported by Rehman, et al. ${ }^{4}$ from Aligarh and India.

Prevalence of donor deferred due to HIV was $0.119 \%$ (80\% $\mathrm{Cl} 0.01 \%-0.13 \%$ ) in our population. (Table 2)

Similar prevalence of $0.02 \%$ was shown by lqbal, et al. ${ }^{1}$ from Multan, Pakistan and $0.11 \%$ by Khalid, et al. ${ }^{18}$ from Islamabad. Pakistan. Higher prevalence was reported as $0.16 \%$ by Tufail, et al. ${ }^{2}$ from Islamabad, Pakistan, $1.59 \%$ by Okoroiwu, et al. ${ }^{8}$ from Sokoto, northwestern Nigeria and $1.37 \%$ by Valerian, et al. ${ }^{7}$ from Moshi, Tanzania.

Prevalence of donor deferred due to diabetes was $0.119 \%(80 \% \mathrm{Cl} 0.01 \%-0.13 \%)$ in our population. (Table 2)

Similar prevalence of $0.05 \%$ was reported by Shahtaj, et al. ${ }^{17}$ from Peshawar, Pakistan.

4.5 Important Note: We have adapted the organization and format of "Marwat's Logical Trajectory of Research Process". ${ }^{25-26}$ We have also adopted the calculation for distribution of a disease from here. All 16 studies cited in ours study have calculated percentages for distribution with number of positive cases as denominator. But in any cross-sectional study, the sample size (including both the disease positive and negative cases) must be taken as denominator for calculation of frequency and distribution both. Hence for all these 16 studies, we have calculated their frequency and distribution taking sample size as denominator. Of course, our results shown here for these 16 studies are different from those given in these studies.

\section{CONCLUSION}

Prevalence of blood donor deferral was $5.55 \%$ in our study, which is almost half of all the cited studies here from global, regional, national and local populations. Prevalence in men was many times higher than women and prevalence of permanent causes was higher than temporary causes. Anemia and $\mathrm{HCV}$ were the two major causes of deferral in our study. Proper donor selection is a key of safe blood transfusion. Appropriate measures are needed to prevent causes of deferral.

Acknowledgment: We acknowledge the support of Dr. Muhammad Marwat (marwatmuhammad@ mail.com) from Gomal Medical College, D.I.Khan, Pakistan to grant us permission to use his "Marwat's Logical Trajectory of Research Process" and to help us in data analysis and writing of the manuscript.

\section{REFERENCES}

1. Iqbal H, Tameezud Din A, Tameezud Din A, Chaudhary FM, Younus M, Jamil A. Frequency and causes of deferral among blood donors presenting to Combined Military Hospital Multan. Cureus 2020; 12(1):e6657. https://doi. org/10.7759/cureus.6657

2. Tufail S, Babar F, Ikram N, Raza M, Abdul-Shakoor $\mathrm{H}$. Blood donors deferral- causes. J Rawalpindi Med Coll 2013; 17(1):119-21.

3. Al Nouri AK, Maghrabi LA, Hamdi SS. Analysis of the most common causes of blood donor deferral in northern Jeddah: A single-center study. J Blood Med 2019; 10(17): 47-51. https://doi.org/10.2147/ JBM.S178822

4. Rehman S, Arif SH, Mehdi G, Mirza S, Saeed N, Yusuf $F$. The evaluation of blood donor deferral causes: a tertiary care centre-based study. J Blood Disorders Transf 2012; 3(5):131. https:// doi.org/10.4172/2155-9864.1000131

5. Hassan U, Azam N, Rahim SK. Blood donation; blood donation perception and willingness in people visiting Rawal General \& Dental Hospital, Islamabad. Professional Med J 2018; 25(6):870-5. https://doi.org/10.29309/TPMJ/18.4491

6. Tariq S, Tariq S, Jawed S, Tariq S. Knowledge and attitude of blood donation among female medical students in Faisalabad. J Pak Med Assoc 2018 Jan; 68 (1):65-70.

7. Valerian DM, Mauka WI, Kajeguka DC, Mgabo M, Juma A, Baliyima L, et al. Prevalence and causes of blood donor deferrals among clients presenting for blood donation in northern Tanzania. PLoS One 2018 Oct 25; 13(10):e0206487. https://doi. org/10.1371/journal.pone.0206487

8. Okoroiwu HU, Asemota EA. Blood donors deferral prevalence and causes in a tertiary health care hospital, southern Nigeria. BMC Health Serv Res 2019 Jul 19; 19:510. https://doi.org/10.1186/ s12913-019-4352-2

9. World Health Organization. The Clinical use of blood in medicine, obstetrics, paediatrics, surgery and anaesthesia, trauma and burns. World Health Organization 2001 [cited 2020 Aug 12]. Available at: https://apps.who.int/iris/handle/10665/42397

10. Zou S, Musavi F, Notari EP, Rios JA, TrouernTrend J, Fang CT. Donor deferral and resulting donor loss at the American Red Cross Blood Services, 2001 through 2006. Transfusion 2008 Dec; 48(12):2531-9. https://doi.org/10.1111 /j.1537-2995.2008.01903

11. Shaz BH, James AB, Hillyer KL, Schreiber GB, Hillyer CD. Demographic variations in blood donor deferrals in a major metropolitan area. Transfusion 2010 Apr; 50(4):881-7. https://doi. org/10.1111/j.1537-2995.2009.02501.x

12. Charles KS, Hughes P, Gadd R, Bodkyn CJ, Rodriguez M. Evaluation of blood donor deferral causes in the Trinidad and Tobago National Blood Transfusion Service. Transfus Med 2010 Feb; 20(1):11-4. https://doi.org/10.1111/j.1365- 
3148.2009.00968.x

13. Birjandi F, Gharehbaghian A, Delavari A, Rezaie $\mathrm{N}$, Maghsudlu M. Blood donor deferral pattern in Iran. Arch Iran Med 2013; 16(11):657-60.

14. Kasraian L, Negarestani N. Rates and reasons for blood donor deferral, Shiraz, Iran. A retrospective study. Sao Paulo Med J 2015 Feb; 133(1):36-42. https://doi.org/10.1590/1516-3180-2013-7110002

15. Sundar P, Sangeetha SK, Seema DM, Marimuthu P, Shivanna N. Pre-donation deferral of blood donors in South Indian set-up: An analysis. Asian J Transfus Sci 2010 Jul; 4(2):112-5. https://doi. org/10.4103/0973-6247.67037

16. Agnihotri N. Whole blood donor deferral analysis at a center in Western India. Asian J Transfus Sci 2010 Jul; 4(2): 116-22.

17. Khan S, Rehman N, Raziq F. Donor deferral: evaluation of causes on pre donor screening. Gomal J Med Sci 2012 Jan-Jun; 10(1): 23-6.

18. Khalid A, Khalid N, Rehan M. Monitoring the spectrum of donor deferrals in a hospital blood bank: a tertiary care hospital experience. J Blood Lymph 2018; 8(2): 214. https://doi.org/10.4172/21657831.1000214

19. Khurram S, Borhany M, Anwar N, Naseer I, Boota $S$, Mirza I, et al. Frequency and reasons of donor deferral prior to blood donation process: a single centre experience. Transfus Med 2017 Feb; 27(1):10-15. https://doi.org/10.1111/tme.12368

20. Sultan S, Irfan SM, Baig MA, Usman SM, Shirazi UA. Insight into donor deferral pattern based on peripheral blood counts: An experience from South Pakistan. Asian J Transfus Sci 2017 JulDec; 11(2):151-5. https://doi.org/10.4103/09736247.214357
21. Safe Blood Transfusion Programme. Government of Pakistan. Standards and guideline for blood bank and transfusion services. [revised 2013 June, accessed 2020 Aug 5]. Available at: http:// sbtp.gov.pk/wp-content/uploads/2019/06/5standards-and-guidelines-for-blood-banks-andtransfusion-services 1

22. Statistics Kingdom. Proportion confidence interval calculator [internet]. Statistics Kingdom; Melbourne, Australia 2007. [accessed 2020 Aug 20]. Available at: https://www.statskingdom. com/41_proportion_confidence_interval.html)

23. Kasraian L, Ashkani-Esfahani S, Foruozandeh $\mathrm{H}$. Reasons of under-representation of Iranian women in blood donation. Hematol Transfus Cell Ther 2020 Jun 17: S2531-1379 (20) 30066-3. https:// doi.org/10.1016/j.htct.2020.03.009

24. Prados Madrona D, Fernández Herrera MD, Prados Jiménez D, Gómez Giraldo S, Robles Campos R. Women as whole blood donors: offers, donations and deferrals in the province of Huelva, south-western Spain. Blood Transfus 2014; 12 Suppl 1 (Suppl 1):s11-s20. https://doi. org/10.2450/2012.0117-12

25. Ain N, Khan S, Marwat M, Khan N, Ahmad I, Ramzan F, et al. Frequency, distribution and determinants of hypertension in adult stroke population of D.I.Khan Division, Pakistan. Gomal J Med Sci 2019 Jul-Sep; 17 (3):81-9. https://doi. org/10.46903/gjms/17.03.2076

26. Marwat M, Ahmad I, Ashiq F, Ali S, Zamir S, Rehman MU, et al. Frequency, distribution and determinants of diabetes mellitus in adult acute coronary syndrome population of D.I.Khan Division, Pakistan. Gomal J Med Sci 2019 Oct-Dec; 17 (4):13143. https://doi.org/10.46903/gjms/17.04.210

\section{CONFLICT OF INTEREST \\ Authors declare no conflict of interest. GRANT SUPPORT AND FINANCIAL DISCLOSURE None declared.}

\section{AUTHORS' CONTRIBUTION}

The following authors have made substantial contributions to the manuscript as under:

Conception or Design:

Acquisition, Analysis or Interpretation of Data:

Manuscript Writing \& Approval:
SK

SK, RT, JQ, FS

SK, RT, JQ, FS

All the authors agree to be accountable for all aspects of the work in ensuring that questions related to the accuracy or integrity of any part of the work are appropriately investigated and resolved. 